\title{
Mathematics Education in the National Curriculum-with Some Reflections on Liberal Education
}

\author{
Lee Don-Hee
}

\begin{abstract}
Mathematics has been recognized and justified to be placed in the prime core of the formal curriculum for general education. In this paper, however, some reflections are made on the national curriculum together with mathematics education in accordance with the tradition of "liberal education." Liberal education is education for liberal men. The basic education of liberal human being is the discipline of his rational powers and the cultivation of his intellect. It has sustained its meaning and value to be different from the vocational training for the purpose of earning one's living. But John Dewey differently contends that the vocational training may claim a pertinent candidate to the position playing a role in cultivating the human mind, the intellect (or intelligence). For Dewey, important is not the content of teaching but rather the intelligence in its operation.Intelligence is "equipped" with some properties that are functionally related to the properties of the problematic situation, which they take on the character of "method." A kind of mental process, "a methodic process," connecting problematic situations and resolved consequences is what Dewey qualified to be "reflective thinking," where the intelligence keeps itself alive and activating for its full operation. Then, we would have two different, but closely related tasks. One is (i) the self-habituation of methodic activity; and the other is (ii) the nurturing of children in methods. The curricular device is bound to gratify a variety of different needs and motives. No matter how worth studying mathematics may be, it can never be learnt unless the body of learning materials are so organized that students may cope with its degree of difficulty settled for the teaching purpose. Then contents must be appropriately selected and efficiently programmed on the part of learners. Learnability is prior to the academic loftiness at least in educational situations.
\end{abstract}

\footnotetext{
L. Don-Hee $(\bowtie)$

Philosophy of Education, Seoul National University, Seoul, South Korea

(C) The Author(s) 2015

S.J. Cho (ed.), The Proceedings of the 12th International Congress

on Mathematical Education, DOI 10.1007/978-3-319-12688-3_8
} 


\section{Why Should We Teach Mathematics?}

For the first nine school years of the elementary and secondary education in Korea, mathematics is one of the major subject-matters of which the national curriculum formally consists. In several partial amendments, mathematics has outdone other competing subjects in the official process of allocating the weekly teaching hours. In spite of the fact that mathematics fails to draw students' favor and popularity, it has been recognized and justified to be placed in the prime core of the formal curriculum for general education, both elementary and secondary.

Mathematical study itself has occupied integral part of the human civilization as well as intellectual life. As a matter of fact, mathematics has been taught as the core subject-matter in the history of school curriculum everywhere in any civilized part of the world. Its system of knowledge, together with its language and method, has been shared among the world intellectual communities more than any other discipline, probably more than any other human undertaking.

Now, however, I would like to raise an unexpected question: Why should we teach relevantly mathematics to all the young people at elementary and secondary levels of education? And, does it really deserve attention as a competitive power in curriculum development?

From the standpoint of social utility, among different points of view, there may be four reasons, at least, why we should teach mathematics in the school. First, to raise mathematical specialists; second, to meet needs of mathematical knowledge required for the advanced level of professional services; third, to promote problemsolving abilities, namely those of logical or formal reasoning; and fourth, to help people to be familiar with basic mathematical knowledge necessitated for the ordinary daily life.

It may be realistically the case that there must be those who devote themselves to study the highly advanced and outstanding mathematics in any civilized society; that mathematical knowledge must be applied to a variety of professional services; that mathematics by its own nature shows us how to make our thinking logically valid and how to solve efficiently complicated problems encountered in our daily life; and that even basic rules or ideas of mathematics help us to see the complexity of the world in organized forms by virtue of its symbolic power.

But it seems to be necessitated to recognize that only a limited number of mathematicians and professionals are in need of training at higher levels, some basic parts of which are already embedded in the national curriculum for the upper or even lower secondary education. A greater part of students say that mathematics is too unintelligible for them to learn, and that it gives them toilsome and boring time in the class room situations. You cannot teach students anything if they are not able, and not willing, to learn it properly. And your instructional device cannot work in teaching mathematics if they extremely hate and stubbornly refuse to learn it at their own will.

In order to see why we should teach mathematics in the school, and what kinds of mathematization should be experienced, I, as a student of philosophy of 
education and, to be sure, a rank outsider, here would like to say something, perhaps what an ordinary consumer of education experiences with reflections on the national curriculum together with mathematics education.

Here, I would like to make some reflections in accordance with the tradition of "liberal education." I believe that the question should be answered in terms of values and implications of liberal education. For it represents, in its very nature of meaning, authentic communications between the human mind and the cultural tradition. But I do not try to make mathematics education fitted into an orthodox admittedly dominant in its tradition, but rather to discuss about how we should understand the idea of liberal education in its consideration with teaching mathematics.

\section{In the Tradition of Liberal Education}

Liberal education is education for liberal men. Originally, as Leo Strauss mentioned, a liberal man was a man who possessed a privilege to behave in a manner becoming a free man, as distinguished from a slave (Strauss 1968, p. 10). A slave is also a human being who lives yet for another human being, his master; he has no life of his own. The master, on the other hand, has all his time for himself, that is, for the pursuits becoming him in the world, with its meaning, of his social and intellectual life.

Nowadays, in the democratic society, however, we may say that a liberal man is a man, a rational being, who is to live under his own will, not other's. By education, one becomes, and maintains oneself, a liberal man in the genuine sense. The basic education of liberal human being is the discipline of his rational powers and the cultivation of his intellect. Historically, it is believed that this discipline can be achieved by the liberal arts, basically the communicational arts, namely reading, speaking, writing, listening, reckoning, and reasoning. The three R's (reading, writing, and reckoning), which always signified the formal discipline, are qualified for the essence of liberal or general education.

In the tradition of liberal education, numeracy, together with literacy, has been integral part of human abilities for the societal life civilized more or less so as to engage in liberal education. Plato especially points out that the mathematical studies develop the soul in two ways: In the first place, they provoke reflection and bring out all the contradictions that lie hid in ordinary opinions based on mere senseknowledge; in the second place, they take him part of the road towards the good which is the goal of all learning and all life (Boyd and King 1975, pp. 34-35).

In his master-work, the Republic, Plato discusses an educational scheme to show how the ideal State might be created out of programs cultivating the mind of the youth. Up to seventeen or eighteen, the children, assumed to be the future rulers, were all to devote themselves to gymnastics and music. After 2 years of physical training, the youth who had proved themselves capable of more advanced studies were to work at the mathematical sciences-arithmetic, geometry, astronomy, and harmonics (the mathematical theory of music) from twenty to thirty. Finally a select group who had shown distinction both of mind and character throughout the whole 
course of their previous training were to spend 5 years in the study of dialect (or philosophy), the science of the good (ideas), before taking their place in the ranks of the "guardians."

There may be at least two different conceptions of liberal education: one is intellectualistic while the other is pragmatic. Among others I want to mention here Mortimer J. Adler as an intellectualist who stands against a pragmatist John Dewey. The idea of liberal education itself was genetically aristocratic, for the truly free man who can live in a manner becoming a free man is the man of leisure. But liberal education is not simply entitled to a kind of program for the free man in a political sense, but also understood differently so as to mention a certain principle overriding activities cultivating the human intelligence and creativity.

For liberal education, Adler maintains that the human reason may be at first trained in its proper operations by the communicational arts, since man is a social animal as well as a rational one and his intellectual life is lived in a community which can exist only through the communication of men. The intellect cannot be accomplished merely by the three R's, but, in addition, through furnishing it with knowledge and wisdom, acquainting it with truth, and giving it a mastery of ideas. At this point, he suggests that the other basic feature of liberal education appears, namely the great books, that is, the master productions in all fields, philosophy, science, history, and belles-lettres. These constitute the cultural tradition by which the intellects of each generation must first be cultivated.

Mortimer J. Adler says:

... If there is philosophical wisdom as well as scientific knowledge, if the former consists on insights and ideas that change little from time to time, and if even the latter has many abiding concepts and a relatively constant method, If the great works of literature as well as of philosophy touch upon the permanent moral problems of mankind and express the universal convictions of men involved in moral conflict-if these things are so, then the great books of ancient and medieval, as well as modern, times are repository of knowledge and wisdom, a tradition of culture which must initiate each new generation. (Adler 1939)

In Adler's conception, liberal education is a kind of program which provides the youth with communicational arts (reading, writing, speaking, reckoning etc.), and thereafter with the intellectual mediator for the constant intercourse between them and the greatest minds in the cultural tradition. Liberal education is learning for its own sake or for the sake of all those self-rewarding activities which include the political, aesthetic, and speculative. It differentiates itself from vocational training which no one should have to take without compensation, and which is just preparatory to work for the sake of earning. (Adler 1951)

\section{Intelligence, Method, and Methodic}

Now, we may ask again "what for liberal education?" It is education to cultivate the human intellect, and thus to liberate the human mind. It has sustained its meaning and value to be different from the vocational training which is confined to learning 
skills for the purpose of earning one's living. Traditionally, it is literate education of a certain kind: some sort of education in letters or through letters, as tools for developing the intellect. It has been conceived to be a kind of program for teaching the youth in subjects, namely liberal arts, and studying the great books reminding oneself of human excellence, of human greatness.

As John Dewey differently contends, however, that there seems to be no relevant reason why we are to confine ourselves to literate education for teaching in socalled liberal arts. Even the vocational training may claim a pertinent candidate to the position playing a role in cultivating the human mind, the intellect (or intelligence). For this qualification, of course, vocational training is also availed of the capacity as efficiently a tool to be utilized as the traditional program in liberal arts.

Dewey says as follows:

\begin{abstract}
... Instead of trying to split schools into two kinds, one of a trade type for children whom it is assumed are to be employees and one of a liberal type for the children of the well-to-do, it will aim at such a reorganization of existing schools as will give all pupils a genuine respect for useful work, an ability to render service, and a contempt for social parasites whether they are called tramps or leaders of 'society.'...

... It will indeed make much of developing motor and skills, but not of a routine or automatic type. It will rather utilize active and manual pursuits as the means of developing constructive, intentive and creative power of mind... the individual may be able to make his own choices and his own adjustments, and be master, so far as in him lies, of his own economic fate... So far as method is concerned, such a conception of industrial education will prize freedom more than docility; initiative more than automatic skills; insight and understanding more than capacity to recite lessons or to execute tasks under the direction of others... (Dewey 1917)
\end{abstract}

For Dewey, what must be important is not whether the content of teaching consists of letters or non-letters for developing the mind, indeed the mind of the liberal man, but rather whether "the human intelligence" can work properly in its operation. Intelligence can work to solve the problem situation, trifling or serious, that we encounter in our daily life, such as conflict with neighbors, discord within the family, crises of confidence in business and the like. We need a social intelligence to solve the problem situation, such as deep economic depression, state security risk, vicious inflationary spiral, chronic rebellion, and the like. Academically, a variety of disciplines, theoretical or practical, are products of intelligence managing to work out of the problem situation where academics struggle with a systematic body of highly complicated ideas and matters. Mathematics is a structure of resolutions painstaking with forms of mathematical intelligence.

Intelligence does not operate vacuously: It is "equipped" with some properties that are functionally related to the properties of the problematic situation. When these properties are systematically distinguished, formulated and organized so as to apply to the problematic situation, they take on the character of "method." Method then is not outside of or divorced from material. Method may be philosophical, literary, scientific, mathematical, or technological. Dewey writes, "The fact that the material of a science is organized is evidence that it has already been subjected to intelligence; it has been methodized, so to say" (Dewey 1916, p. 165). Method then 
is a logical description of intelligence in operation. Indeed, intelligence and method are synonymous.

In this consideration, mathematics as a discipline or a subject-matter may be admittedly said to be a sort of human product subjected to intelligence, thus its material content methodized in such a way that it has characteristically differentiate itself in its properties from other modes of human works.

In the educational discourses, we often refer to "intelligence" as the prime human ability among others to be developed in teaching or training programs. "Habit" is also referred to as objective pertinent to educational activities. But "intelligence" or "abilities" mostly includes those which are characteristically cognitive and self-directive, whereas "habits" mostly represents those which mainly pertain to physical and routine actions. This is the reason why the vocational training makes itself mistakenly different in its mode of learning from the traditional conception of liberal education.

A general theory that accounts for habits and intelligence and their various relationships becomes a matter of our concern. The question here, of course, is what kind of action is both habitual and intelligent: And the problem is to distinguish the appropriate kind of situations for the use of the terms, "habitual" and "intelligent," respectively, to be employed.

If method is a logical description of intelligence in operation, and indeed intelligence and method are synonymous, then we may ask: Could methods be habituated? Could they become habitual? These questions have to do neither with the possibility of forming the habit of adopting methods nor with the evolution of a method into habit. Rather, these questions have to do with the possibility of habituating "methodic" activities. But the habit of methodic activity could still be understood as a habit of translating methods into the pursuit of an end. This sense of "methodic habit" implies a habit of reproduction. The intelligence that has served methods is secondary to the intelligence functioning in methodic activities. For the former intelligence is not activating while the latter intelligence is. Furthermore, the powers that methods may execute are not necessarily powers of intelligence, nor are they human powers. What we actually look for is the habit of methodizing or controlling problem-situations, of pursuing methods, and of utilizing methodized patterns in the pursuit of an end, that is, a methodic habit.

A kind of mental process connecting problematic situations and resolved consequences is what Dewey qualified to be the process of "reflective thinking," where the intelligence keeps itself alive and activating for its full operation.

Dewey's conception of reflective thinking is in somewhat temporal terms, different from a methodological account featuring formal properties. Dewey is not providing a formula, but a temporal account of the activity in which the formula does its work. Dewey's theory of reflective thinking should therefore not be understood to rule out the adoption of ready-made methodic formulae - those which have been already methodized. Indeed, he cautioned us that we ignore these at our peril. He argues that things as methodized represent the office of intelligence, in projection, in pursuit, and in the control of new experience. In short, methodic 
habits are valued habits of intelligence. They are embodied in, or are cases of, intelligence.

Dewey claims that reflective thinking should be an educational aim since it carries with itself qualities significant as educational values (1933, p. 17). In the first place, it emancipates us from merely impulsive and merely routine activity. It enables us to direct our activities with foresight and to plan according to ends-inview, or purposes. Secondly, it enables us to develop and arrange "artificial" signs to remind us by representing in advance not only "existential" consequences but also ways of securing and avoiding them. Thirdly, since an object to which we react is not a mere thing, but rather a thing having a definite significance or meaning, reflective thinking enriches the object with further meanings as we compare a thing or event as it was before with what it is after. Intelligent mastery over the object is obtained through thinking.

Here we would have two different, but closely related tasks. One is (i) the selfhabituation of methodic activity; and the other is (ii) the nurturing of children in methods. The first is based on the assumption that methodic activity, reflective thinking or the problem-solving process, is not only a methodological mechanism for teaching knowledge of substances (or subject-matters) emerging in the system of educational values, but it is also something to teach. This means that methodic activity is not merely a means serving in the pursuit of various educational objectives, but also is itself a candidate for being an educational objective.

But the second task should not be understood as the fact that the educative process is methodic because it is a process of applying the method supposedly common to all disciplines. That is, if all disciplines are cases of method then they should display common properties - common formal properties. The ends of various disciplines differ in form and substance; the means differ in the force of applicability of their theories. But each is an affair of controlled means and ends. To say again, mathematics is a discipline of mathematical method as well as mathematical intelligence.

Methods are symbolic expressions of what is performed in the process of controlled activity. They represent among other matters the material involved. But substantial materials, for example, problems, issues, situations, events, or reports, are not always of a single type in their mode of placement in the means-end relating.

The objective common to all sciences, including mathematics, is assertion making, conclusion drawing, proposition forming, and possibly theory structuring. Each science is a kind of knowledge forging, hypothesis testing, prediction constructing, and so on. Thus, we have physiological and biological knowledge, economic and astronomical facts, geological and biological hypotheses, historical and anthropological reports, and philosophical and mathematical arguments. We sometimes call all these bodies of knowledge-meaning, of course, the fruits of the inquiries of these sciences. All are equally sciences and human achievements according to scientific method. But each is different in the sense that each is proceeding with different problems, materials, concepts, and terminology. Thus it 
seems unlikely that one can learn a method in a specific type of problematic situation without experience in the conduct of dealing in and with that situation.

The implication that the educative process is a process of nurturing children in methods leads to a theoretical corollary that the object of educational research or inquiry may be found in the universe of methods. This is to claim that if there is a universe of discourse, a block of conceptual equipment which more adequately deals with the tasks of educators, it must be the universe of discourse about methods or methodic activities in which intelligence is to be embedded. Mathematics is also methodic in its nature.

\section{Conditions of Mathematics for Liberal Education in the National Curriculum}

Last February, I found an interesting column in one of the issues of the daily newspaper Joong Ang Ilbo that is published in Seoul. It was titled "No Easy and Interesting Math Learning" written by a professor of mathematics, named Yong-Jin Song of In-Ha University. To partly translate into English as follows:

... Mathematics for today has become a systematic discipline which has grown up sophisticated by virtue of great geniuses intelligence in the human history, and thus it must be difficult in its nature for ordinary people to learn. You cannot make yourself master of its hard and tough contents without taking a well-planned course of learning. Mathematics is the supreme product of human intellect such that even its fundamental level requests you to undergo a well-organized training which is somewhat intensive to some extent. To be sure, there exists no mathematics that is easy and, at the same time, interesting; but perhaps rather there may exist such a kind of mathematics that is both difficult and interesting. Many a thing is popular and interesting because of its difficulty: playing a game of go, golf, soccer, computer or the like. (Song 2012)

Professor Song, however, does not mention what kind of mathematics to be taught. Of course, he may presuppose the possibility such that its contents be organized in accordance with the condition of learners describable in terms of age, experience, motivation and cultural orientation. Nevertheless, he seems to assume that the mathematics may be enjoyed exclusively by those who are intellectually equivalent to appreciate of its value. It seems to me that he assumes there exist "the (one and only one in kind) mathematics" which schools should teach to all young people.

If he believes, as Karl Mannheim opposes the possibility of a sociology of mathematics, and as Pythagoreans and Platonists believe, that mathematical truths are eternal objects, not culturally relative (Restivo and Collins 1982), then he may be right in the assertion that we should not be concerned with the degree of difficulty in mathematics education.

But, as Oswald Spengler says that there is no mathematic but only mathematics, we define mathematics as methodic products, we discussed earlier, of intelligence in operation for the struggle with problematic situations. Mathematics is a particular 
mode of experience, distinguishable from other disciplines and arts, and the character of mathematical inquiries vary with cultural toils, and with problematic motives and interests. There may be quite a few different ways of inclusion and exclusion in organizing contents for different orientations.

And if learning values are appreciated, and academic needs are gratified by the experience of mathematical difficulty, the very difficulty of "the mathematics as such," then it confines to a very limited number of people who can intrinsically enjoy the subject-matter, what is called "mathematics," just as a very limited number of few people, the professional or ardent players, enjoy the game, go, golf, and soccer. The difficulty provides no legitimate ground that mathematics may outdo other competing subjects in the competitive process of allocating the weekly teaching hours, and that it can claim to be the prime core of the national curriculum for general education.

We cultivate the human mind (intellect or intelligence, whatever) by the instrumentality of mathematics in association with other teaching-learning programs, that take care of, and improve, the native faculties of the mind. Therefore, mathematics is to deserve a core subject-matter among those worthwhile to teach for liberal education, the finished product of which is a cultured human being. Mathematics, which cultivates and thus liberates the human mind, consists of intrinsic values, that is, those which are good in itself. We do not necessarily enforce it to demonstrate any practical utilities, that is, extrinsic values which are instrumentally good for something other than itself. Even its applied ramifications may be so organized as to materialize their cultivating and liberating powers to the maximum extend. Even in non-academic activities where mathematics is subsidiary, they must be planned to methodically activate the human potentials of creativity and productivity.

Probably, of course, an outstanding group in mathematics can enjoy its intrinsic value at the highly advanced level. And the well-trained professional proficiency in teaching may open up new path into a more sophisticated realm as a benefit to ambitious students. To them mathematics becomes not any more a painstaking burden, but rather an enjoyable game.

The curricular device is bound to gratify a variety of different needs and motives. No matter how worth studying mathematics may be, it can never be learnt unless the body of learning materials are so organized that students may cope with its degree of difficulty settled for the teaching purpose. Then contents must be appropriately selected and efficiently programmed on the part of learners. Learnability is prior to the academic loftiness in educational situations. You cannot enjoy what you are not learnable. The variety may avail with us widely open learning opportunities where many a different mathematical need may be gratified.

In sofar as mathematical education is concerned, we may justifiably say that learning opportunity in its genuine sense be available to the learners, if and only if it is not the case that its course of study is too unequivalent for the students to carry out in the regular school activities. Especially, it is true of the national curriculum system which is assumed to be compulsory to all youngsters. 
Open Access This chapter is distributed under the terms of the Creative Commons Attribution Noncommercial License, which permits any noncommercial use, distribution, and reproduction in any medium, provided the original author(s) and source are credited.

\section{References}

Adler, M. J. (1939). The crisis in contemporary education, The Social Frontier, 5, 141-144.

Adler, M. J. (1951) Labor, leisure, and liberal education, Journal of General Education 6, 43.

Boyd, W., \& Edmund J. K. (1975). The history of western education. 7th Edition. London: Adams \& Charles Black.

Brown, T. (2010). Cultural continuity and consensus in mathematics education, (Special Issue on Critical Mathematics Education) Philosophy of Mathematics Education Journal ISSN 14652978 (Online) No. 25.

Dewey, J. (1916). Democracy and education. New York: The Macmillan Company.

Dewey, J. (1917). Learning to earn, School and Society, 5, 333-334.

Dewey, J. (1933). How to think. Chicago: Henry Regnery Company.

Dewey, J. (1934). Art as experience. New York: Capricorn Books.

Dewey, J. (1938). Logic: The theory of inquiry. New York: Henry Holt and Company.

Restivo, S., \& Randal, C. (1982). Mathematics and civilization: a Word version of the original article from The Centennial Review 26(3), 271-301.

Song Y. (2012). No easy and interesting math learning, (in Korean) Joong Ang Ilbo February 4. (2012. 2. 4.).

Strauss, L. (1989). Liberalism ancient and modern. With a new Foreword by Allan Bloom. Ithaca: Cornell University Press. 